\title{
'Wondering and waiting' after obstetrical brachial plexus injury: Are we underestimating the effects of the traumatic experience on the families?
}

\author{
Carol DeMatteo $\mathrm{MSc}^{1,2,3}$, James R Bain $\mathrm{MD}^{1,4}$, Deborah Gjertsen BHSc OT ${ }^{1}$, Jessica A Harper BSc ${ }^{2,3,4}$
}

\begin{abstract}
C DeMatteo, JR Bain, D Gjertsen, JA Harper. 'Wondering and waiting' after obstetrical brachial plexus injury: Are we underestimating the effects of the traumatic experience on the families? Plast Surg 2014;22(3):183-187.

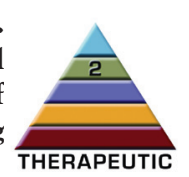

BACKGROUND: Obstetrical brachial plexus injury (OBPI) in children can cause great distress to a family due to uncertain recovery, variability in spontaneous recovery and unclear indicators for surgery.

OBJECTIVE: To investigate the impact of having a child with OBPI on the family and whether the Impact on Family Scale (IoFS) can assist in addressing family concerns.

METHODS: A mixed-method (cross-sectional survey and semistructured interviews) study design was used.

RESULTS: Thirty-eight families of children with OBPI completed the IoFS. Surgery significantly predicted a higher IoFS total impact score $(\mathrm{P}=0.02)$. No statistically significant association between the total impact score and severity or age was found, suggesting that impact on family was not dependent on these factors. Themes that emerged from the interviews included traumatic birthing experience, wondering and waiting, and experiencing surgery.
\end{abstract}

CONCLUSION: All families should receive support and acknowledgement of the widespread impact of OBPI.

Key Words: Child; Evaluation; Family impact; Interview; Obstetrical brachial plexus injury; Questionnaire

$\mathrm{O}$ bstetrical brachial plexus injury (OBPI) results from lateral torsion to the neck or direct traction to the upper extremity during birth. Approximately 1.6 to 2.9 per 1000 infants sustain an OBPI (1), with risk factors including birth weight $>4000 \mathrm{~g}$, shoulder dystocia, multiparity, prolonged labour, assisted delivery, maternal diabetes and breech presentation (2,3). The Narakas system classifies OBPI according to nerve injury severity, from least severe Narakas level I (C5-C6 lesion) to most severe Narakas level IV (C5-T1 lesion with Horner's sign) (4).

Spontaneous recovery for infants with OPBI is variable (30\% to $80 \%$ ) (5) and infants who do not recover spontaneously may undergo microsurgery to repair the damaged plexus. Children fall into a 'gray zone' when the decision regarding the benefits and risk of surgery versus no surgery is unclear (6). Reports vary with regard to outcomes with and without surgery $(1,6,7)$.

Although most of the literature has focused on the biological aspects of OBPI, a growing body of knowledge addresses the effects of this injury on the family. Kerr and McIntosh (8) reported that parental response to OBPI (shock, panic, denial, grief and anger) mimics the bereavement response. Bellew et al (9) questioned the parents of 44 children with OBPI (mean age 27 months; range 12 to 51 months) about early experiences with their child. Parents reported that these times were stressful as they attempted to cope with the functional, emotional and social difficulties related to OBPI. McLean et al (10) administered

\author{
"S'inquiéter et attendre » après une lésion \\ obstétricale du plexus brachial : sous-estimons-nous \\ les répercussions de cette expérience traumatisante \\ sur les familles?
}

\begin{abstract}
HISTORIQUE : La lésion obstétricale du plexus brachial (LOPB) chez les enfants peut susciter une grande détresse dans une famille en raison de l'incertitude quant au rétablissement, de la variabilité du rétablissement spontané et du caractère flou des indicateurs de chirurgie.

OBJECTIF : Examiner les répercussions d'un enfant ayant une LOPB sur la famille et si l'échelle IoFS des répercussions sur les membres de la famille peut contribuer à répondre à leurs inquiétudes.
\end{abstract}

MÉTHODOLOGIE : Une méthodologie mixte (étude transversale et entrevues semi-structurées) a été privilégiée.

RÉSULTATS : Trente-huit familles d'enfants ayant une LOPB ont rempli l'échelle IoFS. La chirurgie prédisait de manière significative un indice d'IoFS total plus élevé $(\mathrm{P}=0,02)$. L'association entre l'indice total et la gravité ou l'âge n'était pas significative. Les répercussions sur la famille ne dépendraient donc pas de ces facteurs. Les thèmes qui ont émergé des entrevues incluaient une expérience d'accouchement traumatisante, de l'inquiétude et de l'attente et l'expérience de la chirurgie.

CONCLUSION : Toutes les familles devraient recevoir du soutien, et les effets généralisés de la LOPB sur leur état devraient être pris en compte.

${ }^{1}$ McMaster Children's Hospital; ${ }^{2}$ School of Rehabilitation Science; ${ }^{3}$ CanChild Centre for Childhood Disability Research; ${ }^{4}$ Division of Plastic

Surgery, Department of Surgery, McMaster University, Hamilton, Ontario

Correspondence: Ms Carol DeMatteo, School of Rehabilitation Science, McMaster University, 1400 Main Street West, IAHS 403, Hamilton,

Ontario L8S 1C7. Telephone 905-525-9140 ext 27805, fax 905-524-0069, e-mail dematteo@mcmaster.ca 


\section{TABLE 1}

Semistructured interview questions for families of children with obstetrical brachial plexus injury (OBPI)

Interview questions
1. Tell us about your OBPI experience
a) Pregnancy
b) Birth
c) First month
d) Surgery decision
e) Post surgery
f) 1 year
g) Raising a child with OBPI
2. What is your understanding of OBPI?
3. What's been the most difficult aspect of this experience?
4. a) What has been the impact on you and your family?
b) Has this affected the relationship between you and your other children?
5. What is the most helpful thing that you have found?
6. Is there anything else that you would like us to know?
7. How would you improve the health care service provided to your child and
your family?
8. Describe your child to us

an appropriate tool for evaluating the burden families of children with OBPI experience.

\section{Participants}

\section{METHOD}

All families who attend the McMaster Children's Hospital $(\mathrm{MCH}$, Hamilton, Ontario) OBPI clinic were invited to participate in the present study. Families returned the consent form and survey by mail or in person if they wished to participate. Initially, 102 families received survey packages, of which 18 were returned due to incorrect mailing addresses.

The present study received ethics approval from the McMaster University Research Ethics Board, and all participants and/or their legal representatives provided informed written consent.

\section{Study design}

The study used the triangulation design method described by Creswell (20): a mixed-method design with equal quantitative/qualitative priority. This included a quantitative cross-sectional survey and qualitative phenomenological interviews.

The IoFS (13) is a 24-item questionnaire focusing on the impact of chronic childhood illness on the family. Participants respond to each item on a four-point Likert scale. The survey provides a validated (2123) 15-item total impact score that indicates the overall impact of the child's condition on the family. The additional IoFS subscales include: financial impact, which measures the economic consequences for the family; general negative impact, which measures the disequilibrium experienced by the caregivers; disruption of social relations, which measures the disruption in social interactions within and outside the family; and coping, which measures coping strategies used by the family to master the stress. No cut-off points for score interpretation have been reported in the literature; however, a total impact score of 15 would theoretically represent no impact and a higher score would indicate more impact.

An occupational therapy student unknown to the family conducted the interviews at $\mathrm{MCH}$. Interview questions (Table 1) were designed to elicit the families' OBPI experience. The interviews were tape recorded and transcribed to ensure accurate data collection.

\section{Analysis}

Survey responses were analyzed using SPSS version 19 (IBM Corporation, USA). Descriptive statistics were calculated, and the study sample was compared with the $\mathrm{MCH}$ total OBPI population using a $\chi^{2}$ test for independence. A one-way ANOVA was used to identify differences in mean IoFS scores across Narakas classifications. Independent sample $t$ tests were used to identify differences in mean IoFS scores between surgery and no surgery families. A stepwise regression analysis was used to establish predictive values of independent variables (Narakas, surgery and age) with IoFS total impact; $\mathrm{P}<0.05$ was considered to be statistically significant.

Qualitative content analysis was used and data collection continued until saturation of themes was achieved (20). Each issue was individually coded, collapsed into categories, grouped into themes and labelled using active words (gerunds). To ensure accuracy and trustworthiness of the data, triangulation and indirect member verfication were used. Specific IoFS item responses were compared with themes to ensure the homogeneity of answers. Clinicians also discussed the results to confirm that the themes were observed in clinical practice.

\section{RESULTS}

\section{Quantitative}

Thirty-eight surveys were returned (response rate 44\%). The first nine families who consented to be interviewed also participated in in-depth semistructured interviews, all of which involved both parents. Table 2 describes the children with OBPI whose families completed the IoFS.

The mean $( \pm$ SD) IoFS total impact score was $24.79 \pm 8.96$ (range 15 to 51$)$. The subscales, financial impact $(4.63 \pm 2.06$; range 3 to 11$)$, general negative impact $(16.61 \pm 5.42$; range 10 to 32$)$, disruption of social relations $(14.13 \pm 5.23$; range 9 to 30$)$ and coping $(7.11 \pm 2.47$; range 4 to 13 ), also showed impact.

Figure 1 illustrates the comparison of IoFS subscale scores across Narakas levels, indicating that there were no significant associations between severity of injury and the subscales. However, a Spearman's rank-order correlation demonstrated that a higher Narakas level was positively correlated with scores of disruption of social relations $(\mathrm{r}=0.432 ; \mathrm{P}=0.008)$ and total impact $(\mathrm{r}=0.365 ; \mathrm{P}=0.024)$.

Independent sample $t$ tests between surgery families $(\mathrm{n}=16$ [42.1\%]) and no surgery families $(\mathrm{n}=22[57.9 \%])$ revealed a significant difference between the groups on the disruption of social relations $(\mathrm{P}=0.018)$ and total impact $(\mathrm{P}=0.020)$ scores, as shown in Figure 2. The surgery group had higher impact scores.

Whether the child underwent surgery significantly contributed to the regression model, accounting for $14.1 \%$ of the total impact score variance $(\mathrm{F}=5.932 ; \mathrm{P}=0.020)$ and an unstandardized beta of -6.733 $(t=-1.504 ; P=0.020)$. The child's age (unstandardized beta $=-0.430$; $\mathrm{t}=-9.46 ; \mathrm{P}=0.351$ ) and Narakas classification (unstandardized beta $=$ 1.022; $\mathrm{t}=0.498 ; \mathrm{P}=0.621$ ) did not add significantly to the model.

\section{Qualitative}

Saturation of themes was reached at nine interviews, indicating no need for future interviews (20). Six key themes were extracted from the data including: traumatic birthing experience, communicating diagnosis, experiencing surgery, wondering, family functioning and supporting environment.

Traumatic birthing experience describes the complications and resulting emotional trauma the family experienced during their child's birth. One mother explained:

I still have flashbacks about the birth...I remember feeling so

scared. It was so unnerving.

The appearance of the baby postdelivery was also distressing. One family stated their child looked "totally battered". As a result of the trauma, families worried about having another baby. One mother:

... went and actually got my tubes tied right away even though me and my husband were talking about having another baby and now I wish I hadn't done it because we would have had another baby. But at the time it was devastating.

Communicating diagnosis refers to the information provided to the family at the time of birth. Information was delayed and inadequate, causing a great deal of uncertainty and stress. One family reported: 
TABLE 2

Descriptive characteristics of children with obstetrical brachial plexus injury (OBPI) whose families participated in the study

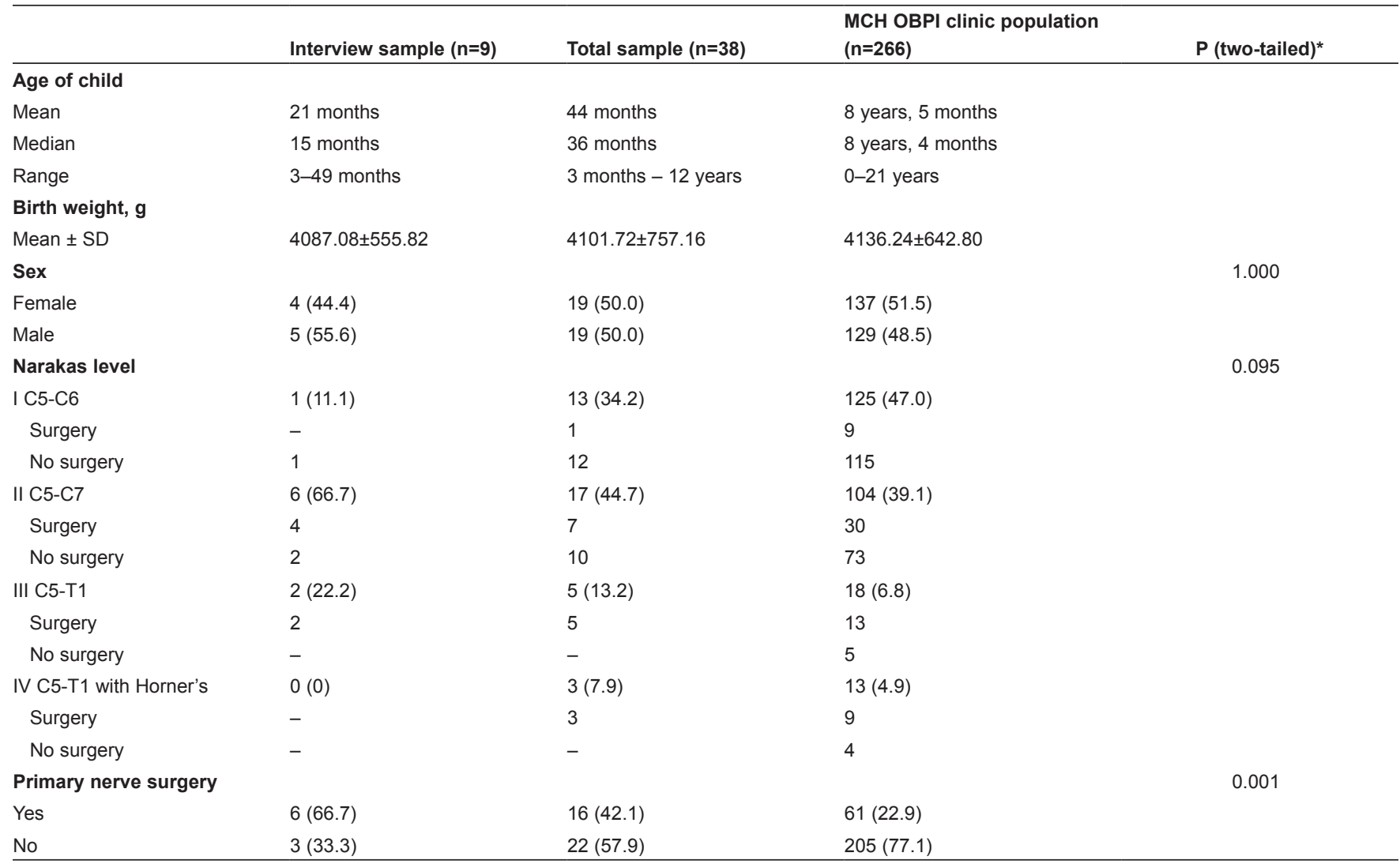

Data presented as $n$ (\%) unless otherwise indicated. * $x^{2}$ test of independence between total sample and clinic population. MCH McMaster Children's Hospital (Hamilton, Ontario)

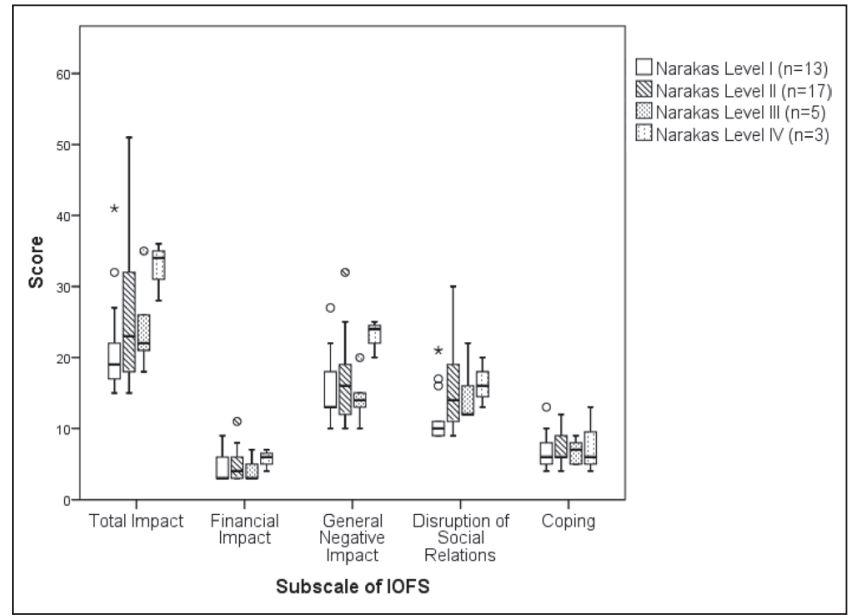

Figure 1) Comparison of scores across Narakas levels on the five Impact on the Family Scale (IoFS) subscales. An ANOVA revealed no significant difference between groups on any of the subscales, including the total impact $(F=1.650 ; P=0.196)$, financial impact $(F=0.461 ; P=0.711)$, general negative impact $(F=2.155 ; P=0.111)$, disruption of social relations $(F=1.556 ; P=0.218)$ and coping $(F=0.072 ; P=0.975)$. Note: Outlier more than 1.5 box lengths from the box edge. *Extreme outlier more than three box lengths from the box edge

Nobody told us what was going on so we had no idea... it was probably three weeks or so before we were told what was going on and how to fix it...oh, I was very upset - here I was with an infant we had no idea what was wrong and no one was sharing.

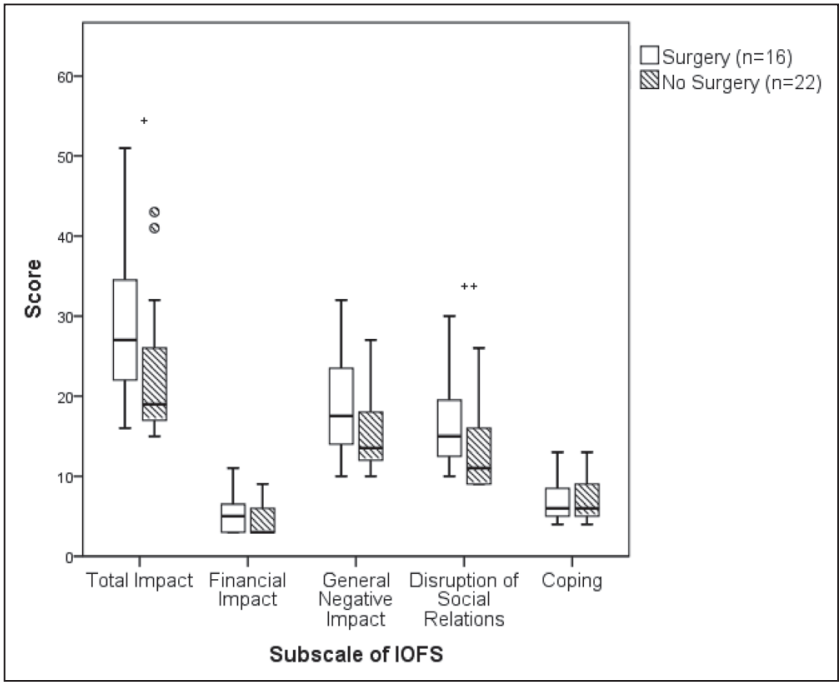

Figure 2) Comparison of scores between surgery and no surgery families on the five Impact on Family Scale (IOFS) subscales. The surgery families had significantly higher total impact $(t=2.436 ; P=0.020[+])$ and disruption of social relations $(t=2.475 ; P=0.018[++])$ scores. There were no significant differences in financial impact $(t=1.440 ; P=0.159)$, general negative impact ( $t=1.903 ; P=0.065)$ or coping $(t=-0.090 ; P=0.929)$. Note: Outlier $>1.5$ box lengths from the box edge. *Extreme outlier $>3$ box lengths from the box edge 
The manner in which information was delivered to parents was also stressful. One family shared:

Because again it seemed like doctor after doctor and nurse after nurse wouldn't give us straight answers... when I questioned her [the doctor] about what happened she totally avoided, she wouldn't talk to me about it. The nurses were very matter of fact about it, oh she'll be fine, she'll be fine and that wasn't true. This is going to be affecting her the rest of her life.

Because the doctors were unable to answer their questions, many families relied on 'hearsay' information and the Internet to learn about their child's condition. One family suggested that:

Right off the bat there should be more education about this, thank goodness you guys [OBPI clinic] do... I wish someone with knowledge about this was standing beside that doctor because... sorry (crying) because I can remember like it was yesterday and he walked out of the room and I was left sitting there, I had no idea what it was, there was no one to help us.

'Wondering' refers to the waiting and wondering experienced with respect to the child's recovery and future functional capabilities. One family expressed "not knowing made me insane...". Wondering and waiting were also indicated in the post surgery phase. A family reflected that:

as we look back now... it's a lot of unanswered questions leading up to it [surgery], now after surgery, how's he really going to be? Is he going to be $100 \%$ ? Is he going to be $50 \%$ ? Is it not going to work at all?

Experiencing surgery refers to the decision to undergo surgery, the surgery itself and the postsurgical recovery. Two families expressed strong concerns about surgical complications, including the potential death of the child. Four families believed that seeing their child attached to medical equipment after surgery was difficult. One parent explained:

Having him in the hospital and seeing him bandaged up... pretty much immobilized... that's probably the hardest.

Family functioning describes how OBPI affected the nuclear and extended family. Four families found the experience impacted their family negatively. One family shared that their daughter's sibling:

had a really bad period because my time was so devoted to her with all the OT I was doing with her.

Five families believed that the experience also strengthened family bonds. One mother indicated:

Me and my husband went through some hard times emotion-

ally within our marriage... I think if anything it may have

brought us closer... he's opened up a lot more, like talking

about his feelings.

The OBPI experience also impacted the families' relationship with other relatives. One participant became "distant" from her husband and relatives, "... so the family didn't know the extreme of it".

Supporting environment refers to the support the family received from health care providers, family and friends, and how this assisted them through their child's recovery. All nine families indicated that the physician and occupational therapists at the OBPI clinic were extremely supportive and valuable throughout the recovery process. For example:

... the people here have been great. The way that they're able to deal with you. You know they have a very calm manner and you don't feel rushed.

In addition, four families believed that the support of family and friends was extremely beneficial for gathering information. Three parents expressed how valuable speaking with other families who have experienced OBPI was for them because they have "a lot of the same concerns as we do".

\section{DISCUSSION}

The present study demonstrated that having a child with any severity of OBPI has a significant long-term impact on the family because families still report impact up to 12 years postinjury. Whether the infant underwent surgery was significantly associated with the families' total impact and disruption of social relations scores. However, age and injury severity (4) were not significantly associated with total impact, yet a positive correlation was found between Narakas level and total impact, indicating a trend toward larger familial impact for children with more severe injuries.

Similar to our findings, Bellew et al (9) found that all families experienced distress. In addition, Karadavut and Uneri (11) found a trend toward higher levels of depression and anxiety for mothers of infants with more severe injuries. McLean et al (10) also found that mothers who perceived their child to have a higher level of disability had significantly greater levels of psychological distress. Because surgery was associated with higher stress in the present study and surgery is generally performed on children with more severe injuries (6), the case for an association between a more severe injury and higher impact becomes stronger.

All of the parents we interviewed expressed that their child's delivery was very traumatic, which supports previous findings (9). In fact, the description of flashbacks and degree of sadness and fear parents relived during the interviews were very similar to symptoms of posttraumatic stress disorder (24), yet this diagnosis had not been conveyed to any family members in our study or reported in other literature. Although we did not specifically test for parental depression, these descriptions of post-traumatic stress reaction are evidence of high emotional impact on the family, beyond what may be anticipated by the health care team evaluating the infant's biological injury.

The themes extracted from our qualitative data also correspond to others in the field $(9,11,12)$, which suggests that families of children with OBPI may have common experiences despite institutional and environmental differences.

After a child is born with OBPI, families must wait for a diagnosis, wait to see if their child will recover spontaneously, wonder if their child needs surgery, wait to see how their child recovers from surgery and, ultimately, wonder how this injury will impact the remainder of their child's life. This wondering and waiting is heightened by the lack of best practice guidelines for surgical decision making beyond the extremes of a mild or very severe injury (6). The watching and waiting for recovery without clear definitive action can be extremely stressful because it often takes months to reach a decision or the outcome of spontaneous recovery is realized. Our themes of wondering and experiencing surgery were echoed by the themes described by Beck (12) of the burden of a lifelong emotional heartache, worrying and questioning as child grows older, and time-consuming therapy and surgery, which were identified through interviews with 23 mothers of children with OBPI (range three months to 10 years).

Themes of supporting environment and communicating diagnosis highlighted the importance of social support and communication for the family throughout this stressful experience. Similarly, Bellew et al (9) reported that families were highly dissatisfied with how the initial diagnosis was communicated and the information provided. In particular, families we interviewed emphasized the importance of clear communication from health care professionals of the OBPI diagnosis and expectations for recovery. The parents in our sample also emphasized the importance of support from family, friends, health care professionals and other parents. In addition to a negative impact, some parents reported that the injury also had a positive impact by creating stronger ties with friends and family.

Compared with other conditions of childhood, families of children with OBPI score lower than families of children with chronic illnesses $(13,14)$, HIV infection (16) and low birth weight $(17,18)$ when scored using the 24-item IoFS total impact score (13). However, OBPI families had considerably higher scores than families of children who 
sustained a traumatic brain injury (19). Scoring lower on the IoFS than other conditions may not accurately reflect the families' level of distress. As already discussed, there were many factors of concern to families not captured by the IoFS.

The IoFS captured the themes of family functioning and supportive environment; however it did not capture the traumatic birthing experience, wondering, communicating diagnosis or experiencing surgery themes. Therefore, the IoFS may not be the best tool to provide accurate information on levels of stress or guide interventions for this population.

Limitations to the present study are due to the small sample size. Only three families had a child with a Narakas IV injury, none of which were included in the interviews. This must lend caution to interpreting the finding that injury severity was not associated with the total impact score. However, the results still indicate a clinically important level of impact and distress experienced by all families. Although the children were between three months and 12 years of age, most were young. Additionally, the present study was cross-sectional in design, which limits its ability to capture the overall experience.

\section{CONCLUSION}

For families, the experience of OBPI can be highly traumatic and longstanding. Families experience many stressful factors including the birth, surgical decision process, and 'wondering and waiting' not captured by the IoFS. An OBPI of any severity impacts the family; however, families of children who undergo surgery demonstrate more impact. All families should receive acknowledgement of the widespread impact of this injury. They should be provided with comprehensive intervention that includes emotional support for the parents and siblings, as well as physical care of the infant.

ACKNOWLEDGEMENTS: The authors thank Danielle Clarke, Rudo Adams and Jeff Mah, Occupational Therapy MSc candidates for their hard work in helping them peform this study. They also thank the families from the McMaster Children's Hospital OBPI clinic for sharing their experiences.

\section{REFERENCES}

1. Pondaag W, Malessy MJ, Dijk JG, Thomeer RT. Natural history of obstetric brachial plexus palsy: A systematic review. Dev Med Child Neurol 2004;46:138-44.

2. Dunham EA. Obstetrical brachial plexus injury. Orthop Nurs 2003;22:106-16.

3. Walle T, Hartikainen-Sorri AL. Obstetric shoulder injury. Associated risk factors, prediction and prognosis. Acta Obstet Gynecol Scand 1993;72:450-4.

4. Narakas AO. The treatment of brachial plexus injuries. Int Orthop 1985;9:29-36

5. Brown T, Cupido C, Scarfone H, Pape K, Galea V, McComas A. Developmental apraxia arising from neonatal brachial plexus palsy. Neurology 2000;55:24-30.
6. Bain JR, DeMatteo C, Gjertsen D, Hollenberg, RD. Navigating the gray zone: A guideline for surgical decision making in obstetrical brachial plexus injuries. J Neurosurg Pediatr 2009;3:173-80.

7. McNeely PD, Drake JM. A systematic review of brachial plexus surgery for birth-related brachial plexus injury. Pediatr Neurosurg 2003;38:57-62.

8. Kerr SM, McIntosh JB. Disclosure of disability: Exploring the perspective of parents. Midwifery 1998;14;225-32.

9. Bellew M, Kay S, Webb F, Ward A. Developmental and behavioural outcome in obstetric brachial plexus palsy. J Hand Surg 2000;25B:49-51.

10. McLean LA, Harvey DH, Pallant JF, Bartlett JR, Mutimer KL. Adjustment of mothers of children with obstetrical brachial plexus injuries: Testing a risk and resistance model. Rehabilitation Psychol 2004;49:233-40.

11. Karadavut KI, Uneri SO. Burnout, depression and anxiety levels in mothers of infants with brachial plexus injury and the effects of recovery on mothers' mental health. Eur J Obstet Gynecol Reprod Biol 2011;157:43-7.

12. Beck CT. The arm: There is no escaping the reality for mothers of children with obstetric brachial plexus injuries. Nurs Res 2009;58:237-45.

13. Stein RE, Riessman CK. The development of the impact-on-family scale: Preliminary findings. Med Care 1980;18:465-72.

14. Kolk AM, Schipper JL, Hanewald GJ, Casari EF, Fantino AG. The impact-on-family scale: A test of invariance across culture. J Pediatr Psychol 2000;25:323-9.

15. Juniper EF, Guyatt GH, Feeny DH, Ferrie PJ, Griffith LE, Townsend M. Measuring quality of life in the parents of children with asthma. Qual Life Res 1996;5:27-34.

16. Lesar S, Maldonado YA. The impact of children with HIV infection on the family system. Families in Society. J Contemp Human Serv 1997;272-9.

17. Cronin CM, Shapiro CR, Casiro OG, Cheang MS. The impact of very low-birth-weight infants on the family is long lasting: A matched control study. Arch Pediatr Adolesc Med 1995;149:151-8.

18. Gennaro S. Preterm low-birthweight infants: Health and family outcomes. Fam Community Health 1995;17:12-21.

19. Coster WJ, Haley S, Baryza MJ. Functional performance of young children after traumatic brain injury: A 6-month follow-up study. Am J Occupational Ther 1994;48:211-8.

20. Creswell JW. Research Design: Qualitative, Quantitative, and Mixed Method Approaches. Washington DC: Sage Publications, 2003.

21. Stein R, Jessop D. PACTS Papers/AECOM: Tables Documenting the Psychometric Properties of a Measure of the Impact of a Chronic Illness on a Family. Bronx: Department of Pediatrics, Albert Einstein College of Medicine; 1985.

22. Stein RK, Jessop DJ. The impact on family scale revisited: Further psychometric data. J Dev Behav Pediatr 2003;24:9-16.

23. Williams AR, Piamjariyakul U, Williams PD, Bruggeman SK, Cabanela RL. Validity of the revised impact on family (IOF) scale. J Pediatr 2006;149:257-61.

24. American Psychiatric Association. Post-traumatic stress disorder. Diagnostic and Statistical Manual of Mental Disorders, 4th edn Text revision (DSM-IV-TR). Washington DC: American Psychiatric Association, 2000. 